\title{
El problema de la violencia en la cosmovisión de Mainländer*
}

\author{
Sandra Baquedano \\ Universidad de Chile \\ sandrabaquedano@uchile.cl \\ https://orcid.org/0000-0001-5408-5204
}

\begin{abstract}
Resumen: ¿Es posible que un filósofo promueva, con el ejemplo, la violencia como medio para la resolución de conflictos? Sócrates, Descartes, Rawls, Wittgenstein o Jonas, entre otros, son casos de quienes terminaron por distintas causas enrolándose en ejércitos o participando de algún modo en diversos conflictos bélicos. Muchos lograron a pesar de ello no mezclar sus filosofias con algo ajeno a la misma. Este artículo se propone indagar en la La filosofia de la redención de Mainländer a fin de detectar los peligros que acarrea enaltecer el uso de la violencia, elevando el amor a la patria a nivel de sabiduría filosófica. Este aspecto será identificado como el más delicado de su pensamiento, lo que explicará por qué se prescinde aquí de calificarlo de filósofo y se aluda a él como pensador en la medida que ciertas reflexiones que resultan ser esenciales en determinadas materias pudieron terminar siendo contaminadas por un fanatismo nacionalista. Esto abrirá la posibilidad de pensar en un criptobelicismo de base en algunos aspectos de su obra. Palabras clave: violencia; patriotismo; egoísmo; fricción; redención
\end{abstract}

\begin{abstract}
The Problem of Violence in Mainländer's Worldview". Is it possible for a philosopher to, by example, promote violence as a means of conflict resolution? Socrates, Descartes, Rawls, Wittgenstein or Jonas, among others, are cases of those who ended up for different reasons enlisting in armies or participating in some way in various wars or conflicts. Despite this, many managed not to mix their philosophies with something alien to it. This article aims to investigate Mainländer's The Philosophy of Redemption in order to detect the dangers of exalting the use of violence, by elevating love of the country to the level of philosophical wisdom. This aspect will be identified as the most critical of his thinking and will explain why he isn't qualified as a philosopher in this paper, but referred to as a thinker. This is sustained to the extent that certain reflections that turn out to be essential in some matters could end up being contaminated by a nationalist fanaticism, opening the possibility of thinking about a base of crypto-bellicism in some aspects of his work.
\end{abstract}

Keywords: violence; patriotism; selfishness; friction; redemption

\footnotetext{
*Este artículo es resultado del proyecto Fondecyt 1190021.
} 


\section{Antecedentes biográficos de Philipp Batz}

Philipp Batz (1841-1876) es un pensador que aún resulta ser desconocido para una gran mayoría. Su pseudónimo Mainländer es escogido por el lugar de su tierra natal, Offenbach, situada a orillas del río Main. El término en alemán significa "de la región del Main".

Por deseos de su padre, recibió una formación de comerciante y, cuando era muy joven, emigró a Italia para ocupar un puesto en una casa comercial. Su fuerte inclinación humanista lo llevó a aprender italiano y leer a Dante, Petrarca, Boccaccio y Leopardi en la lengua original. El período napolitano fue duro y de largas depresiones, las cuales exacerbaron su deseo de encontrar una liberación al tormento que le significaba la existencia. La intención que tenía de acelerar el curso de su vida fue haciendo crónica su fijación por ser soldado y dar la vida por ideales que él consideraba superiores. La posibilidad de perecer combatiendo no solo era reflejo de su temprano patriotismo, sino también de su idealización de la muerte, expresiones que atraviesan tanto su vida como su obra. El rasgo común que comparten los personajes de sus creaciones literarias es que, en general, están dispuestos a morir por diversas causas: por sus amores, sus ideales, etcétera.

Cuando Mainländer decide volver a Alemania para hacerse cargo de la fábrica de cueros de su padre, justifica su retorno aludiendo, hacia fines de 1862, a un ferviente amor a la patria como la más preciada joya que puede poseer un hombre: "Ni por todas las alegrias de esta tierra y del Paraíso, abandonaría la sagrada tierra donde nací y me crié; ahí está mi sitio en el 'seno del Estado'... Ustedes, muchedumbre ingenua, que llaman patria suya a todo el mundo, olvidan con esto que solo puede obrar en virtud de la humanidad quien tiene un sólido fundamento nacional, y es ahí donde de vez en cuando puede soñar, en el seno de su intima tierra"1.

Además de conducir la firma del señor Batz-responsabilidad que nunca fue de su total agrado- tuvo que afrontar la pérdida de su madre, con quien

\footnotetext{
1 Sommerlad, F., "Aus dem Leben Philipp Mainländers", en: Müller-Seyfarth, M. (ed.), "Die modernen pessimisten als décadents": von Nietzsche zu Horstmann. Texte zur Rezeptionsgeschichte von Philipp Mainländers Philosophie der Erlösung, Wurzburgo: Königshausen und Neumann, 1993, p. 99. Esta y el resto de las traducciones del alemán al español son propias.
} 
tenía un fuerte lazo afectivo. Trató de contrarrestar esa aflicción, abocándose de lleno a la vida intelectual e intentando, en fallidas ocasiones, hacerse soldado con la idea de sacrificarse por una Alemania unificada. Se figuraba dar la vida en el campo de batalla, con lo cual pensaba acelerar en el fondo el tormento que le provocaba vivir, pues la vida, en términos generales, no le era algo distinto de esa lucha. Después de estos episodios en los que no irrumpía de hecho en el campo de batalla ni se hacía soldado, se consagraba con mayor intensidad a las letras, el teatro y la filosofia. Como autodidacta y en soledad, estudiaba y repasaba clásicos de antropología, historia natural, religión, política, ciencias sociales, poesía alemana y, en especial, filosofia. Se dedicó a leer a Heráclito, Platón, Aristóteles, Escoto, Locke, Berkeley, Hume, Hobbes, Helvetius, Herbart, Condillac, Fichte, Hegel y Schopenhauer².

Pese a una serie de avatares económicos que lo llevaron a trabajar algunos períodos de su vida en un Banco de Berlín, nunca dejó de cultivar sistemáticamente su erudición. Como resultado de arduas jornadas, dedicado luego por completo a su obra en Offenbach, concluyó en 1874 La filosofía de la redención, la cual apareció publicada en 1876. Su perturbante belicismo le decía que había forjado una "buena espada". Un poco antes, había escrito: "En otoño habrás terminado tu significativo sistema filosófico. Sin duda sentirás un gran vacío en ti. ¿Cómo quieres llenarlo?... ¿ ¿No será necesario que te des paz? La teoría está completa; ahora ha de llegar la praxis; ¿y qué otra acción práctica podría seguir a la eminentemente teórica que ingresar al glorioso Ejército alemán?...”’3. Al poco tiempo se incorporó en Halberstadt al regimiento de Magdeburgo como coracero. Escogió el servicio más rudo en el cuerpo de caballería. Decía que no quería ser de esas personas que se aprovechan de los beneficios públicos sin retribuir con nada ni cumplir con su deber hacia el Estado. Afirmaba que quería luchar por la elevada meta o bien de la humanidad.

Era consciente de que su actividad teórica estaba lista, pero no lo era respecto del hecho que la práctica estaba siendo introducida por un sesgado y peligroso sentimiento nacionalista. En Mi historia como soldado, Mainländer se retrata como un camarada ejemplar que, a los treinta y tres años, asumió las labores más duras. Se subordinó a las duras órdenes de jóvenes menores que él de manera incondicional y por amor a ellos: "Descendí de las placenteras relaciones burguesas a las rudas condiciones de los soldados, llenas de privaciones.

2 Cf. Mainländer, P., Die Macht der Motive. Literarische Nachlass von 1857 bis 1875, v. IV, Hildesheim/Zúrich/Nueva York: Georg Olms, 1999, p. 325.

3 Sommerlad, F., “Aus dem Leben Philipp Mainländers”, p. 104. 
Había trabajado casi exclusivamente con la pluma y la cabeza, deleitándome con los genios de todos los tiempos, y ahora debía cardar los caballos, limpiar el establo, blandir el sable y darme por satisfecho con el estrecho círculo de pensamientos de las clases más bajas del pueblo"4. Frente a quienes tenían puestos inferiores, decía guiarse por un principio de justicia y humanidad para conducirlos a un Estado superior. En marzo de 1875, manifestó que ya había pasado por todo como soldado. Concibió los apartados que versan sobre el verdadero idealismo, la trinidad cristiana y el socialismo. Además, proyectó crear una Escuela Superior Libre a la que posteriormente denominó Orden de Caballeros del Espiritu, de supuesto corte filosófico, que lucharía por el destino del género humano. Había establecido ya los estatutos de la Orden del Grial.

Si bien planeaba permanecer tres años en el servicio militar, solo duró uno; luego, abandonó el Ejército y regresó a Offenbach. Ahí terminó algunos ensayos que, póstumamente, fueron editados por su hermana Minna y que fueron denominados como el segundo tomo de su obra capital. También escribió una autobiografia y una breve novela, tras lo cual sufrió un colapso espiritual. Sentía un gran vacío y no dejaba de pensar la consecuencia entre teoría y praxis. Tiempo antes le había confesado a su hermana Minna que no podía trabajar para el pueblo y el Estado más que con la pluma.

El último día de marzo de 1876 recibió en Offenbach la primera edición de La filosofia de la redención. A las pocas horas, en la noche que va del 31 de marzo al primero de abril, Mainländer se ahorcó siguiendo las premisas ontológicas forjadas por él mismo en su obra capital.

\section{El origen del universo en la destrucción originaria y la proliferación de la} lucha hacia el no ser

La filosofia de la redención plantea que, al comienzo de todo, solo hubo una unidad simple (einfache Einheit) que dejó de existir en cuanto tal, que transformó su esencia, desintegrándose totalmente en el universo: "La desintegración en la multiplicidad fue el primer movimiento, y todos los movimientos que le siguieron son solo su prolongación... Así, Dios devino mundo, cuyos

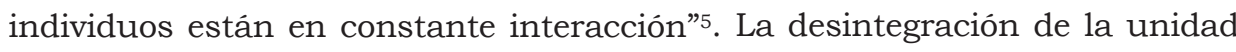
premundana (vorweltliche Einheit) no es distinta al surgimiento del universo

4 Ibid., p. 109.

5 Mainländer, P., Die Philosophie der Erlösung, v. I, Hildesheim/Zúrich/Nueva York: Georg Olms, 1996, p. 109. 
de la multiplicidad. De esta forma, Mainländer representa al universo en movimiento hacia el no ser en máxima crispación y tensión ${ }^{6}$.

El pensador de Offenbach concibe la omnipotencia divina en relación con la esfera del ser, que lo era todo. Fuera de sí, no existía nada que limitara a Dios. Sin embargo, plantea que precisamente ese nihil habría sido su único obstáculo, el cual le impidió, al autoaniquilarse, descansar de inmediato en el no ser. Es decir, el autor sostiene que Dios no era una omnipotencia frente a su capacidad de destruirse, de dejar de existir por sí mismo. No obstante, si bien su ingreso en la nada no fue instantáneo, fue el tránsito lo que dio origen a la vida, abrazando todo en el universo consciente o inconscientemente el acto de no ser. Ese tránsito a la nada no es un curso eterno, pues el universo no surgió por un acto de creación, sino más bien por uno de agotamiento de voluntad divina, resultado del acto lógico de no ser. Por consiguiente, presenta el mundo como el medio para lograr dicho fin. Para su consumación final en el nihil negativum, explica que la suma total de fuerzas presentes en cada fragmento ha de estar madura para la muerte, y de este modo, por su procedencia, todo se encuentra en una correlación dinámica.

La fragmentación originaria de la unidad simple trascendente marcó la tendencia del curso vital del campo inmanente, es decir, del resto de los movimientos posteriores, proliferando las más diversas contradicciones en todos los ámbitos ${ }^{7}$. La desintegración de la unidad en la multiplicidad continúa extendiéndose en su descarga energética, en un curso irreversible de fricción (Reibung) que se encuentra aún presente existiendo, pero que deviene hacia su extenuación.

Con su potente impulso e instinto primario, la voluntad consiste en su afán implicado en el movimiento retardador, el cual, si bien imposibilita la consumación inmediata, va rumbo al no ser. Sin embargo, dentro de este tránsito, las voluntades viven, desean, se empecinan, obstinan y quieren ${ }^{8}$. Las voluntades individuales de vivir (die individuellen Willen zum Leben), impulsadas a luchar por su existencia con el fin de asegurarla y afirmar sus intereses, entran en disputa, fricción y roce, como si en el fondo persiguieran un fin distinto al cual se dirigen. Sin embargo, en lo más hondo, lo que quieren no es vivir, ya que la vida es solo un medio para alcanzar el fin en el no ser. A diferencia de la voluntad de vivir schopenhaueriana, esta cosmovisión concibe bajo cada fuerza

\footnotetext{
Cf. Mainländer, P., Die Macht der Motive. Literarische Nachlass von 1857 bis 1875, v. I, p. 86.

Cf. ibid., p. 300.

Cf. ibid., p. 97.
}

ARETÉ Revista de Filosofía, v. XXXIII, 1, 2021 / e-ISSN 2223-3741 
existente una dimensión más profunda de la voluntad que, en lo profundo, quiere descansar, simplemente morir.

El ser aparece, de esta manera, como la tendencia y energía innatas que van sin representación a consumar su meta en el no ser. Entre sí, van formando parte de un inconsciente, arraigado en el yo de cada individuo, el cual no es de carácter universal. De este modo, cada uno de esos fragmentos corresponden a voluntades individuales de morir que -entre el desgaste, el sufrimiento propio de la lucha vital- van moviéndose y entrando en constante fricción al mortificar sus fuerzas con el objetivo de alcanzar en algún momento la redención de sî en la muerte absoluta, el no ser o nihil negativum.

\section{El problema de la violencia: parafilia militar y patriotismo}

Con un son de indolencia en el planteamiento, Mainländer sostiene que no importa cómo se desencadene la redención, la muerte final: "Da exactamente lo mismo cómo (wie) sus individuos, consagrados a la muerte absoluta, se hundan en el exterminio" ". Señala que el pensador tampoco se lamentará por los millones de seres humanos que las migraciones germánicas, las cruzadas y todas las guerras lanzaron a la muerte. De esta manera, su reflexión y lenguaje respecto al cuidado y respeto por la vida del otro resultan ambiguos: "La humanidad completa está consagrada al exterminio (Die ganze Menschheit ist der Vernichtung geweiht)"10.

El intento platónico de purificar, liberar y elevar el alma por sobre el cautiverio del cuerpo y del mundo sensible hacia el verdadero ser encuentra una reformulación moderna en la máxima de Montaigne: "Filosofar es aprender a morir". Esta transmite -en el ejercicio de un móvil reflexivo diáfanamente pacífico- un mensaje de desprendimiento, que no es necesariamente incompatible con la noción de ahims ${ }^{11}$ de las milenarias sabidurias orientales. Dista de tal compatibilidad y sosiego el tenor de muchas afirmaciones presentes en La filosofia de la redención. En su análisis ético-político, no queda siempre claro cómo es que se pueda preparar al ser humano para la muerte. En la antesala de un país que ayudó a gestar la Primera Guerra Mundial y que fue uno de los

9 Ibid., p. 289.

10 Ibid., p. 315.

11 En sánscrito el término alude a la no violencia y al respeto a la vida. Considerado lo opuesto a himsa (violencia), la paz que encarna ahimsa se traduce en no hacer daño a ningún ser capaz de sentir. Este móvil antiespecista constituye uno de los principios rectores del jainismo, siendo su noción e implicancias también centrales en el hinduismo y el budismo. 
mayores responsables de las barbaries cometidas durante la Segunda Guerra Mundial, se extrañan alusiones explícitas en la obra que la desmarquen de un aprendizaje sobre la muerte que implique cualquier adoctrinamiento o programa de formación, el cual incite a la gente, a un pueblo, a un país o a sus fuerzas armadas a la aniquilación del otro. Al contrario, fuertes alusiones patriotas y protonacionalistas anteceden peligrosos discursos nacionalistas, recogidos en lo que hoy se conoce como el segundo tomo póstumo de La filosofía de la redención ${ }^{12}$.

Para Mainländer, la noción schopenhaueriana de la negación de la voluntad de vivir no es más que una expresión de la afirmación de la voluntad de morir, la cual inconscientemente, de acuerdo con su ley cósmica e individual, se manifiesta en la tendencia del ser a querer retornar al reposo absoluto, a la no acción, a la propia muerte, la no-existencia o la desaparición. Ahora bien, se precisó de un personaje como Freud para rehabilitar en todo su alcance psicoanalítico la existencia de la pulsión de muerte (Todestrieb) ${ }^{13}$. considerándose además a Mainländer -también en el contexto del psicoanálisis y a pesar de las diferencias en el abordaje- como el verdadero mentor del principio de nirvana (Nirwanaprinzip) ${ }^{14}$. La tendencia a satisfacer impulsos agresivos, que persiguen en el fondo la destrucción de la materia y la reinserción en el estado inorgánico, suele manifestarse mediante expresiones violentas hacia uno o hacia el resto. Si bien la thanatofilia mainländeriana no ha de ser asociada con la perversa necrofilia ${ }^{15}$-y se diferencia a su vez de aspectos medulares del

\footnotetext{
${ }^{12}$ Cf. Mainländer, P., Die Philosophie der Erlösung, v. II, pp. 339-426.

${ }^{13}$ En los marcos del psicoanálisis el término fue propuesto originalmente en Spielrein, S., "Die Destruktion als Ursache des Werdens", en: Jahrbuch für psychoanalytische und psychopathologische Forschungen, 4 (1912), pp. 465-503. Luego, fue desarrollado en extenso, aunque no exactamente en el mismo sentido, por Freud, a lo largo de su obra, por ejemplo, en Jenseits des Lustprinzips de 1920, y también, en el escrito de 1924: "Das ökonomische Problem des Masochismus", en: Theorie des Unbewußten (1898-1927). Sobre una primera aproximación en castellano respecto a esta relación, véase: Burgos Cruz, O. F., "Sobre una posible influencia de Mainländer en Freud", en: Tlamati Sabiduria, v. VI, 2 (1999), pp. 6-18; y, del mismo autor: Philipp Mainländer. Actualidad de su pensamiento, Chilpancingo: Universidad Autónoma de Guerrero, 2019, pp. 19-36.

${ }^{14}$ Cf. Lütkehaus, L., Nichts, Zúrich: Haffmans, 1999, pp. 250-251. Según consigna el mismo Freud, recoge la expresión Nirwanaprinzip de la psicoanalista Barbara Low.

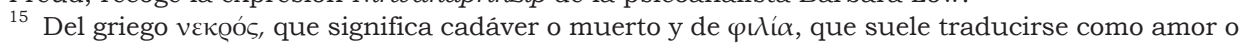
atracción, la necrofilia fue definida como una parafilia que se caracteriza por sentir una atracción sexual y emocional hacia los cadáveres. En este sentido, el psiquiatra Richard von Krafft-Ebing habría acuñado esta connotación del término en la obra Psychopathia Sexualis de 1886.
} 
posterior análisis más amplio que desarrollara Fromm del término ${ }^{16}$, su amor a la muerte se traslapa, en este contexto, con profundas complejidades que abarcan la seducción y atracción por las fuerzas armadas. Tras tanta guerra y conflicto bélico, ¡cuántos monumentos se han erigido! ¿De qué actos heroicos tanta glorificación? Sucesos que implicaron destrucción, sadismo o el mero deseo de matar al enemigo.

Mainländer sostiene que el Ejército ayuda a embellecer el cuerpo de los individuos y no solo lo considera una institución relevante para la educación estética del hombre porque esculpe y tonifica el físico de los soldados, sino porque además cultiva el sentido de la belleza. En su obra, el autor deja entrever una atracción tanto por los movimientos regulares de sus miembros en las unidades de las tropas como por la fuerte instrucción militar y sus maniobras. Todas estas le resultan bellas: "Una institución importante para la educación estética del hombre es el Ejército. No solo se forjan los cuerpos de los soldados por los medios mencionados, sino que también se cultiva su sentido de la belleza con los bellos movimientos regulares, propios del individuo como de las unidades de las tropas, ya que la fuerte instrucción militar y las fluidas maniobras resultan bellas"17. Este deleite sensual fue antecedido desde temprano en su vida por un instinto sexual de sometimiento, al límite de desear poner su cuerpo y vida ciegamente a disposición de otro por causas que las fuerzas armadas glorifican: "Rogaba con ser soldado... Cuando me traslado a aquella época y reflexiono sobre mi estado, solo puedo decir que fui arrastrado por un demonio salvaje, el cual inconscientemente se precipitaba hacia una meta. Curiosamente este instinto se revelaba en parte. Así que, un poco después de que mis padres se negaran rotundamente a mi petición, le dije a un amigo: 'Tengo un deseo extraordinario de someterme incondicionalmente, de una vez

${ }^{16}$ Cf. Fromm, E., The Anatomy of Human Destructiveness, Nueva York/Chicago/San Francisco: Holt, Rinehart and Winston, 1973, pp. 325-368. Para Fromm la necrofilia es uno de los grandes males de la humanidad, la cual está relacionada con la ausencia de amor en la sociedad. Un mayor Desarrollo de esta idea se encuentra en: Fromm, E., The Dogma of Christ, Londres/Nueva York: Routledge Classics, 2004, p. 132; y en: The Heart of Man, Its Genius for Good and Evil, Nueva York: Harper \& Row, 1964, pp. 37-61. El necrófilo es un ser que actúa de un modo mecánico, entrando en una dinámica de reificación con el entorno y los otros seres vivos que lo rodean, a quienes trata como cosas. Para satisfacer sus intereses y sed de consumo requiere que el mundo completo termine transformándose en fuente de explotación. En su afán de control y dado que lo único seguro que tiene en vida es la propia muerte, acaba por desearla. Según Fromm, la necrofilia se evidencia con máxima claridad en el desprecio a la mujer, las grandes construcciones de hormigón armado, la industria armamentista y la tecnofilia. Cf. Fromm, E., "Prophets and Priest”, en: Shoenman, R. (ed.), Bertrand Russell, Philosopher of the Century. Essays in his Honour, Boston: Little, Brown and Company/The Atlantic Monthly Press, 1968, p. 78.

17 Mainländer, P., Die Philosophie der Erlösung, v. I, p. 142. 
y por completo, a otro, de hacer el trabajo más bajo, tener que obedecer ciegamente'. Este deseo aparece constantemente en mi vida, y yo, sin embargo, soy en el fondo el ser más necesitado de libertad. Creo que en aquel entonces este deseo estaba relacionado con el impulso sexual, aunque no puedo dar una explicación sobre esta conexión" ${ }^{18}$.

En la mirada retrospectiva al joven de catorce años que fue, retrata cómo su inclinación fue poseída por una especie de demonio salvaje que lo impulsaba a ser soldado. Testimonia la búsqueda de un placer por ser humillado y hacer penitencias, dejando abierta la posibilidad de si su confesión anida en el fondo una soterrada parafilia militar. Esta sería una tendencia que quizás él mismo intentará racionalizar con posterioridad, explicar de alguna forma o sublimar a través de expresiones patriotas, protonacionalistas -como las que aparecen en una constante a lo largo de esta obra- o a través de la apología que hace de la castidad. No es casual la necesidad que tuvo de contar que antes de servir al Ejército visitó la tumba de su madre para jurar con solemnidad frente a ella: "virginidad hasta la muerte" (Virginität bis zum Tode) ${ }^{19}$.

Según Mainländer, el movimiento de la humanidad incluye el enfrentamiento de grandes pueblos y Estados. Además, considera eminentemente moral luchar contra otros países en pro del Estado ideal (idealer Staat). En la lucha por alcanzarlo, elogia el auténtico patriotismo, legitimando tácitamente el uso de la violencia para hacer justicia por mor de la humanidad con prácticas que no diferencia del movimiento del destino, hacia el cual cree avanzar en sintonía con lo que ha elevado a nivel de mandamiento filosófico: "Este saber, este conocimiento que se impone a cada pensador, puede enardecer la voluntad: de un modo gradual o con la celeridad de un rayo. Luego, ingresa por completo en (in) el movimiento de la generalidad, y entonces, nada con la corriente. Ahora lucha con valentía, alegria y amor en el (im) Estado. Mientras el movimiento de la humanidad se siga produciendo a gran escala, sobre todo a partir de la operación conjunta o el enfrentamiento de grandes pueblos y Estados individuales, también luchará con [mit] el suyo (eventualmente, junto a sus aliados) contra [gegen] otros Estados en pro [für] del Estado ideal. Llegando a este punto, arde en auténtico patriotismo, en la auténtica justicia, en el auténtico amor a la humanidad: está situado en [in] el movimiento del destino; actúa en sintonía con su mandamiento, y con gusto; es decir, sus acciones son eminentemente morales"20.

${ }^{18}$ Mainländer, P., Die Philosophie der Erlösung, v. IV, p. 312.

19 Sommerlad, F., "Aus dem Leben Philipp Mainländers", p. 108.

${ }^{20}$ Mainländer, P., Die Philosophie der Erlösung, v. I, p. 214. 
En este contexto, aduce las razones por las cuales el movimiento hacia el Estado ideal no lleva una impronta moral, a diferencia de las acciones de los individuos que sí pueden ser de esa índole en relación con el movimiento del conjunto, pues la moral descansa en el sujeto. Sin embargo, aclara que tal movimiento se realiza con una violencia irresistible y que la redención de la humanidad depende de la solución de los problemas sociales. Ahora bien, ese movimiento social descansa en el de la humanidad, es decir, plantea que este sigue avanzando con la misma violencia que arrastra tanto a quienes quieren como a quienes se resisten a seguir su curso infalible ${ }^{21}$.

En el capítulo "Ética", Mainländer retoma la figura del héroe sabio como aquel que se entrega por completo a lo comunitario y consagra su vida a la humanidad, ayudándola en su conducción al Estado ideal, al nivel civilizatorio más elevado. En un estado de penurias y necesidad, las preocupaciones vitales impedirian cultivar en plenitud el conocimiento. Sin embargo, resuelta la cuestión social, saciadas las necesidades que el mundo puede ofrecer, la voluntad se puede volver consciente de la nulidad de la vida y apagarse con mayor facilidad, rumbo al objetivo final de ser redimida de sus dolores. En el capítulo "Política", a su vez, se alude al carácter violento de los tránsitos, las revoluciones y las guerras que depara el curso de la historia, insertándose la figura de aquellos buenos y justos (Gute und Gerechte) que se han de encargar de que estos procesos ocurran con la menor atrocidad posible ${ }^{22}$.

Por un lado, esta cosmovisión identifica el amor a la patria, la justicia y el amor al prójimo como virtudes cardinales ${ }^{23}$. No obstante, al no expresarse Mainländer en determinados pasajes de manera respetuosa, empática o compasiva frente a otros pueblos, etnias, Estados o países, queda a veces la duda de cuál es el prójimo al que se refiere, con quién se es benevolente, si es una máxima cristiana extensible a todo el mundo o si es extensible solo a quienes comparten su misma bandera ${ }^{24}$. Además, hay que recordar que Mainländer

${ }^{21}$ Cf. ibid., p. 301.

${ }^{22}$ Cf. ibid., pp. 302-303.

${ }^{23}$ Cf. ibid., p. 212.

24 "Alemania será siempre el más interesante y significativo de todos los países civilizados porque está formada por una nación que se ha conservado en su pureza" (Mainländer, P., Die Philosophie der Erlösung, v. II, p. 490). "El ario, orgulloso y bello, no pudo más que sentirse como un ser de clase superior frente al semisalvaje de costumbres rudas, figura fea y piel oscura, y tiene que haber sentido una verdadera aversión a mezclarse sexualmente con él" (Mainländer, P., Die Philosophie der Erlösung, v. I, p. 236). Sobre Fichte, quien pronunció sus conocidos Discursos a la nación alemana (1808), señala que es "un honor para nuestra nación, el más genial político filósofo de todos los tiempos" (Mainländer, P., Die Philosophie der Erlösung, v. II, p. 348). 
vivió en tiempos de guerra y que él mismo fue soldado. Por otro lado, si bien describe un Estado ideal sin guerras, ensalza la aceleración o el proceso de fricción, roce y desgaste sin rechazar el uso de la violencia para alcanzarlo, lo cual puede esconder, en la ambigüedad del discurso, no solo un criptobelicismo abstracto, sino un protonacionalismo en agresiva evolución. Este aspecto tan delicado de su pensamiento ha sido en general evitado hasta la fecha, sobre todo en Europa, en círculos enfocados en torno a Philipp Mainländer y en los cuales parece generar renuencias el hecho de enfrentar estos temas. El inconveniente de la idolatría ( $\varepsilon i \delta \omega \lambda$ o $\lambda \alpha \tau \varrho \varepsilon i ́ \alpha)$ que se pueda tener hacia algún pensador, respecto al que parcialmente se evadan o excluyan del análisis problemáticas como la recién planteada, es que no ayuda en este caso a desmarcar la filosofia de la legitimación del uso de la violencia como herramienta del discurso filosófico. Esta es una instrumentalización presente en La filosofía de la redención que ha de ser reconocida como tal para así poder luego enfrentarla y explicitar su rechazo.

Cuando desde la infancia se le hace creer a un pueblo que es portador de una "pureza" o de una misión especial "exclusiva" respecto al resto, se lo vuelve más permeable a engendrar un menosprecio hacia los demás. Los nacionalismos tienden a enseñar puntos de vistas parciales sobre ciertos hechos históricos, alimentados mediante conmemoraciones de hitos o actos presentados como heroicos en los que muchas veces se impuso la violencia y que implicaron la crueldad de los vencedores. La historia muestra que los daños que un país puede ejercer contra los que considera sus enemigos no llevan a un estado de paz que los proteja para siempre. Fomentar el orgullo de un pueblo entero exacerbando el sentimiento de superioridad nacional, elevando a sabiduría la fortaleza e insensibilidad moral de su gente respecto a otros pueblos, pasando por alto que muchas riquezas adquiridas provienen de países extranjeros o alimentando el orgullo que provoca haber vencido y humillado al otro implican abanderar e institucionalizar como virtud cardinal esta forma de egoísmo organizado. Grandes potencias mundiales empeñaron todos sus esfuerzos en maximizar sus recursos fisicos e intelectuales a fin de lograr ser más poderosas.

No de la solidaridad universal, sino de la unión política y económica de un pueblo, es que emerge como tal la nación para lograr determinadas metas. Sin embargo, la historia muestra que, en el intento de cumplirlas, el espíritu de conflicto y conquista ha prevalecido por sobre el de la cooperación y tolerancia. Un buen contrapunto frente al patriotismo protonacionalista mainländeriano queda reflejado en la postura adoptada por Tagore-férreo oponente al gobierno 
británico en la India-, quien sostiene lo siguiente: "Todas las grandes naciones de Europa tienen sus víctimas en otras partes del mundo, lo que no solo atrofia su empatía moral, sino también su empatía intelectual" 25 . El poeta hindú es enfático además en señalar que el mal de la nación descansa en ella misma: "La nación con toda su parafernalia de poder y prosperidad, sus banderas y sus himnos piadosos, sus oraciones blasfemas y los truenos artificiales de sus fanfarronadas patrióticas, no puede ocultar el hecho de que el mayor de los males que la acosan es la Nación misma... No tiene otro deseo que explotar las debilidades del resto del mundo"26. Es pertinente en este contexto rescatar también la perspectiva de Tagore, debido a que, en el caso de Mainländer, aun cuando él estudia diversas sabidurias orientales, vemos que el problema de la violencia en su pensamiento hace que su amor a la patria diste mucho de heredar las bondades del pacifismo oriental. Abogar por un futuro con menos violencia implica superar las relaciones basadas en el sentimiento de orgullo y egoísmo nacional recién expuesto.

Bajo los efectos de un estimulante tan potente y adictivo como el nacionalismo, pueblos enteros -al transferir su responsabilidad moral al culto organizado de la nación- han perdido la conciencia de la perversión moral que arrastra poner en práctica agresivas ideologías de egoísmo para la mera obtención de poder y riquezas.

Es cierto que la voluntad de morir mainländeriana excede los peligros que pueden arrastrar los patriotismos y otros fanatismos del género humano. Además de verificársela a diario en los cementerios, comparte un télos cosmológico común al mismo destino que corren, en general, los cuerpos celestes que están en constante tensión, fricción y lucha. Son considerados materia viva en proceso de morir y no ser más. Ahora bien, de no entenderse la noción de "exterminio" y sus derivados en cuanto "muerte de sî", en el sentido de que todo lo vivo morirá, es decir, que la muerte es el fin y el término de la vida, este tipo de pensamiento queda vulnerable a cualquier tipo de manipulaciones o interpretaciones sensacionalistas, más explosivas quizás que los mismos arranques violentos y patriotas que el autor fue capaz de prever.

\footnotetext{
${ }^{25}$ Tagore, R., Nacionalismo, Corriente Basús, F. y S. Chaparro (trads.), Madrid: Taurus, 2012, p. 83.

${ }^{26}$ Ibid., p. 63. 


\section{El egoísmo en la cosmovisión sufriente de Mainländer}

En La filosofia de la redención se sostiene que en todo el universo solo hay voluntades individuales que únicamente tienen el afán primordial de vivir y mantenerse en la existencia, lo cual sería un esfuerzo común a las demás especies. En el caso de la voluntad humana, su individualidad es concebida como un todo, un ser para sí cerrado o simplemente egoísmo (Egoismus) que igualmente se aferra a la vida. Lo distintivo radica en el reconocimiento que Mainländer plantea de dos variantes volitivas fundamentales. Por un lado, quiere la existencia, pero de una determinada forma, es decir, mediante el carácter y temperamento que le es propio. Esto es así ya que en el fondo todas las cualidades de la voluntad son solo distintas configuraciones suyas adoptadas a partir del egoísmo, que es el núcleo más íntimo de su individualidad. Por otro lado, el egoísmo del ser humano se diferencia del resto en que no solo se manifiesta como instinto de conservación, sino también como un impulso hacia la dicha suprema. Las voluntades individuales motivadas por este móvil luchan por alcanzar su bienestar. Constantemente, quieren saciar todos sus deseos y creen que así obtendrán la felicidad. La ilusión estriba en que, tras un deseo cumplido, surge otro, en una cadena que no es distinta de la vida misma, tal como es deseada por el egoísmo natural (natürlicher Egoismus).

Sobre estas formas de egoísmo y sus implicancias éticas, aclara que, como parte de la naturaleza e independiente del Estado y los poderes respectivos que ejercen su potestad sobre sí, el ser humano, así como cualquier otra especie, es una individualidad cerrada en sí misma. A su vez, esta quiere la vida de una determinada forma, pero este afán es obstaculizado por otros individuos que poseen la misma ansia. De esta forma, las voluntades egoístas, dispuestas unas contra otras, se dañan mutuamente; consecuentemente, en la lucha por la existencia, vence el más fuerte o el más astuto. En el estado natural se recalca que todo le está permitido a su egoísmo: no hay Estado ni religión que lo limite en buscar y escoger los medios para beneficiarse. Al verdadero poder que se enfrenta es al de las muchas otras voluntades individuales que, al igual que él, quieren vivir y conservar de un modo aplastante la propia existencia. Ahora bien, al salir del estado natural, el egoísmo queda en parte restringido por el Estado y aquello que no es capaz de limitar se plantea que fue refrenado de alguna manera por la religión ${ }^{27}$. Al surgir cada acción humana de una determinada individualidad y un yo en particular, este pensamiento considera, en

${ }^{27}$ Cf. Mainländer, P., Philosophie der Erlösung, v. I, p. 185.

ARETÉ Revista de Filosofía, v. XXXIII, 1, 2021 / e-ISSN 2223-3741 
general, ese actuar como egoísta, pues, conforme a su naturaleza, persigue la propia felicidad. Toda acción humana, la mejor o la peor, es egoísta y solo se diferencian en el grado en que lo son.

En términos generales, se distinguen en el capítulo "Ética" tres tipos de acciones humanas: las ilegales, las legales y las morales, a pesar de que todas ellas provengan del egoísmo y sean egoístas. Las dos primeras surgen del egoísmo natural, mientras que las acciones morales son resultado de uno depurado (geläuterter Egoismus). El conocimiento es valorado como una facultad que permite ir más allá del limitado egoísmo propio de la individualidad hacia uno depurado en el que se aspira al bien común. Ahora bien, para la solución de la cuestión social, se apela en esta obra al conocimiento filosófico de la relación existente entre el individuo y la colectividad. Este pensamiento aboga por una eudemonía comprometida con una praxis social de envergadura. En este contexto, el eudemonismo explica la motivación de cualquier persona -sea del criminal o del santo- a obrar conforme a lo que le provoque bienestar, aunque ocurra de un modo evidente o encubierto tras refinados disfraces altruistas. Sin excepción, todos dentro de esta cosmovisión -desde militares, criminales, a sabios místicos y filósofos- forman parte del proceso universal que es calificado de necesario y no de índole moral.

Desde esta perspectiva, todos son egoístas. Sin embargo, egoísmo y ética no solo no se excluyen entre sí, sino que el egoísmo es conditio sine qua non de su ética eudemónica. Si bien Mainländer reconoce su obra como continuación de las doctrinas de Kant y Schopenhauer, rechaza este aspecto central de la ética prescriptiva y descriptiva respectivamente, ya que no concibe que la ausencia de toda motivación egoísta sea un referente válido para calificar una acción como moral. Deshecha a la vez el núcleo de la ética schopenhaueriana basada en la compasión considerada como el único móvil moral auténtico.

$\mathrm{El}$ autor de El mundo como voluntad y representación enseña que el individuo, cuando es capaz de abandonarse a sí mismo en el padecimiento del dolor ajeno para ver más allá de los fenómenos individuales que distancian al "yo" del "tú", traspasa el Velo de Maya y capta el dolor común emanado de una única voluntad de vivir que subyace bajo cada ser. La compasión proviene del hecho de ver que el verdadero yo no existe solo en el propio individuo, sino en lo resultante de todos los demás. Solo la compasión puede vencer al egoísmo. Al liberarse del principii individuationis, todo dolor, ya sea el de uno como el del más ajeno, puede ser padecido con la misma intensidad en un estado de consciencia que alivia al otro de su sufrimiento. 


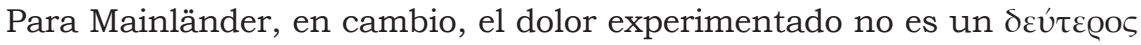
$\pi \lambda$ oũ $\varsigma^{28}$ que lleve con mayor facilidad mediante la compasión a la dimensión de un sufrimiento común, más originario, a saber, la toma de consciencia de una única voluntad universal de vivir. Su forma de entender la compasión no libera a la voluntad individual del yo que la está sintiendo. Por consiguiente, cualquier forma de aliviar al otro de su sufrimiento es clasificado como un obrar siempre egoísta. No la compasión, sino la voluntad enardecida por el conocimiento de que el no ser es mejor que el ser es el fundamento o principio supremo de la moral mainländeriana.

Cabe notar que el pensador de Offenbach no explicita una diferenciación entre dolor y sufrimiento. En cualquier caso, el sufrimiento para él es parte de un engranaje que se debe terminar de desintegrar. Los fragmentos que correspondieron a la unidad simple ya no pueden volver a unirse ni salir menos de la respectiva voluntad individual de vivir y de morir que padecen en lo más profundo de su esencia.

\section{Fricción y redención al fin}

La cosmología mainländeriana presenta un universo donde, dentro de la fricción en constante aumento, se evidencia su ley suprema: la ley del sufrimiento. Cada individuo lucha por conservar su existencia y perpetuarla a través

\footnotetext{
${ }^{28}$ La "segunda navegación" o la "segunda mejor manera de viajar" es una expresión utilizada en la navegación cuando se ha de remar por no haber un viento favorable. Véase Estobeo, Florilegium, Gaisford, T. (ed.), v. II, Leipzig, 1823, 9, p. 376). El modismo es utilizado comúnmente por Platón en Fedón 99d y Filebo 19c, y se aplica a la búsqueda de la verdad. Se ha convertido en proverbial para indicar un camino más duro y dificil, pero a veces más seguro para alcanzar un fin, como en este caso es la navegación, que, en ausencia de condiciones óptimas, se realiza con remos frente a la que, sin adversidades, se realizaria de manera fácil y serena a vela. Schopenhauer aplica el $\delta \varepsilon v ́ \tau \varepsilon \varrho ం \varsigma \pi \lambda$ oũ $\varsigma$ a su filosofia también: $C f$. Schopenhauer, A., Die Welt als Wille und Vorstellung, v. I, Stuttgart/Fráncfort del Meno: Suhrkamp Taschenbuch Verlag, 1986, §68. Esta segunda forma de viajar presupone una primera, la cual proviene del sufrimiento de toda vida meramente reconocido, que se siente y se hace suyo únicamente mediante el conocimiento. Sin embargo, ocurre que, en muy pocos casos, se da la circunstancia de que el puro conocimiento sin el dolor padecido logra traspasar el principium individuationis para terminar finalmente reconociendo y asimilando cualquier sufrimiento del mundo como el propio. Schopenhauer no niega la existencia de casos en los cuales el mero conocimiento pueda lograrlo y emanciparse del principio de razón subordinado a la voluntad, hasta finalmente terminar negándola. Solo sostiene que, pese a que sea esta la mejor forma de renunciar a la voluntad, no es, sin embargo, la más usual. La mayoría se encamina en la renuncia a través de esta "segunda mejor manera de viajar", que es la segunda mejor vía en relación con cualquier vía de afirmación de la voluntad de vivir. Por lo tanto, el calificativo alude más bien al destino antes que al medio, una meta que termina anulándose a sí misma al consumarse en la nada. Ambos modos de viajar son posibles únicamente

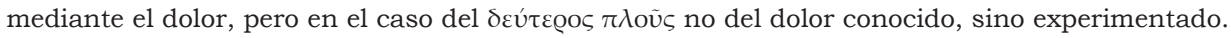


de la procreación. Al hacerlo, directa o indirectamente, provoca y padece dolor, con lo cual debilita las fuerzas suyas o las del resto en una dinámica que, en general, rige la ley de la historia marcada por el sufrimiento ${ }^{29}$.

Se plantea que únicamente en la política es posible constatar el debilitamiento resultante de las aspiraciones de todos sus miembros. No se le atribuye a ese movimiento un curso moral, pues se realiza con una violencia implacable. Superficialmente se aboga que tiende al Estado ideal. Sin embargo, en profundidad se enfatiza que una detención en este no es posible y que se dirige igualmente hacia la muerte absoluta: "Este movimiento no puede llevar una impronta moral, pues la moral descansa en el sujeto, y solo las acciones del individuo (Einzelnen) pueden ser morales (moralisch) frente (gegenüber) al movimiento del conjunto. Se realiza solo a través de una violencia irresistible, y es, como se determina generalmente, el destino omnipotente de la humanidad, el que tritura y quiebra como si fuese vidrio todo lo que se le pone por delante, aunque sea un Ejército de millones"30.

Como el movimiento unitario del mundo es solo obra de una unidad simple premundana, este pensamiento no concilia libertad y necesidad en el campo inmanente. Lisa y llanamente, por el contrario, se afirma que en el mundo no existe la libertad. Todas las adversidades que se padecen, se considera que han sido elegidas antes del mundo, pues constituyen la mejor forma de lograr el objetivo, ser definitivamente redimido: "Su esencia (demonio y espíritu) y el azar lo llevan fielmente (treu) a través del dolor y la voluptuosidad, a través de la alegría y el duelo, a través de la felicidad y la desdicha, a través de la vida y la muerte, a la redención que él quiere" ${ }^{31}$.

La permanente fricción puede elevar la fuerza espiritual del ser humano, volverla más fresca, vigorosa, pero, por otro lado, puede corromperla de un modo generalizado, llevándola a la decadencia que igualmente conduce a la aniquilación.

En La filosofía de la redención se interpreta el Estado como la forma general adoptada por la civilización. Mediante diversas configuraciones, esta desarrolla según la ley del sufrimiento, la cual es su ley capital, caracterizada por debilitar a la voluntad y fortalecer el espíritu. Asume a su vez formas históricas más específicas: la económica (ökonomische), la política (politische) y la

${ }^{29}$ Cf. Mainländer, P., Philosophie der Erlösung, v. II, p. 510.

${ }^{30}$ Véase Mainländer, P., Die Philosophie der Erlösung, v. I, p. 227.

${ }^{31}$ Ibid., p. 357. 
espiritual (geistige). Luego, de manera más precisa, es subdividida en distintas leyes recopiladas en detalle al final del capitulo "Política".

Dado el contexto histórico cercano y en el que estuvo inmerso Mainländer, ve tras sucesos históricos cómo la Revolución francesa y las guerras napoleónicas -ambas, con sus logros y atrocidades-, con absoluta evidencia, son muestra del movimiento fundamental del género humano, aquel que va de la vida hacia la muerte absoluta ${ }^{32}$. A su vez, pronostica que el Estado social y democrático, la eliminación de la miseria y el amor libre no conducen a un paraíso terrenal, sino al Estado en el que se efectúa del mejor modo la redención de la existencia. Precisamente, el Estado es presentado como el lugar donde la humanidad puede desenvolver con mayor plenitud su voluntad y sus capacidades espirituales. Por la gran ley del debilitamiento de la fuerza se plantea que puede alcanzarla más rápido, de ahí que el Estado aparezca como una instancia especial donde puede surgir la fricción requerida para la redención. Sin embargo, este desgaste conlleva un aumento del sufrimiento y de la sensibilidad ante tal padecimiento. El fortalecimiento del espíritu (die Stärkung des Geistes) debilita la voluntad en forma directa -pues se potencia a costa de ella- y también de manera indirecta, a través de un creciente sufrimiento y anhelo de paz ${ }^{33}$.

El dolor y el sufrimiento son consustanciales a la vida, y la humanidad se encuentra en camino al no ser. Este pensamiento ofrece el consuelo de que, en algún futuro, todos serán acogidos en los brazos de la muerte para descansar de los dolores que no resulta posible saltarse ni evitar. Incluso en el más perfecto de los Estados, se tiene que nacer con dolor, padecer determinadas enfermedades, las pérdidas de otros y la propia muerte con la decadencia en perspectiva. Al reconocer de forma clara y distinta que, en esencia, toda vida es sufrimiento y, en la consciencia del espíritu, presión, fatiga y dolor espiritual, esa misma esencia conducirá, mediante la proyección del estado feliz, a la redención que se persigue.

En la figura del filósofo inmanente (der immanente Philosoph), es realzada la imagen de aquel que ve en todo el universo el profundo reflejo del anhelo de no ser, aquel que sigue con su mirada la nada, la cual parece avanzar en todas las esferas celestiales pregonando por la redención. Este clamor encuentra en esta cosmovisión un alivio, pues asegura que absolutamente todos, tras el placer y el dolor, las dichas y los tormentos, la vida y la muerte, encontrarán la paz

${ }^{32}$ Cf. ibid., p. 286.

${ }^{33}$ Cf. ibid., p. 284.

ARETÉ Revista de Filosofía, v. XXXIII, 1, 2021 / e-ISSN 2223-3741 
del corazón (Herzensfrieden), la absoluta aniquilación (absolute Vernichtung). Todos serán borrados para siempre del libro de la vida, es decir, serán finalmente redimidos.

En los seres humanos, se plantea que no solo filántropos o quienes practicaron la castidad merecen y pueden hacerse partícipes de la redención, sino también quienes fueron consumidos por la corrupción, la voluptuosidad, el hastío y el odio, por lo cual se pierden los medios y principios claros. Al final, en unos y otros la llama ardiente de la voluntad se va apagando hasta el titilar de un fuego inestable que en su fragilidad terminará igualmente por extinguirse. Todos serán en algún momento derribados por el destino en la oscura noche del exterminio, pues habrán pagado ya su liberación con el mero hecho de haber vivido, ya que en el fondo la vida es considerada sufrimiento.

Más allá de las tinieblas de la vida, el sabio reconoce la luz de la muerte, después de la tormenta de la voluptuosidad, el descanso en la plácida paz de la bóveda etérea, en cuyo brillo terminará de extinguirse con la liberación de sí, la redención de su vida.

\section{Conclusión}

El problema de querer justificar el uso de armas, en vista de defender los intereses personales o los de la patria contra quienes están preparados para imponer supuestamente por la fuerza fines egoístas y perversos, supone en el fondo que en el mundo hay portadores del bien y vectores del mal. Pero, ¿quién distingue a los unos de los otros? ¿Mainländer en cuanto coracero de Halberstadt? ¿Aquellos que comparten la misma patria o los que están del lado de uno? Son muchos los pasajes en los que el amor a la muerte es idealizado en la manera de alcanzarlo a través de causas específicas como dar la vida por la patria.

Tener la convicción de que existe gente buena y mala en sí, de una vez y para siempre, dependiendo del país al que pertenezcan o la bandera que enarbolen, es insostenible en términos filosóficos. Combatir la violencia con acciones más violentas conduce a dinámicas que, de ser afirmadas, suelen convertir a los supuestos buenos en malos. Creerse bueno o defender únicamente los intereses de quienes hipotéticamente lo son puede resultar tremendamente perjudicial para los oprimidos y su entorno, imposibilitando en el futuro sanar las relaciones que han sido dañadas. Innumerables dolores han sido provocados mucho antes por quienes se han arrogado el derecho de legitimar e institucionalizar 
la violencia para prevenir el mal del que eventualmente podrían ser víctimas. Muchos conflictos bélicos se desencadenan precisamente por la instrumentalización de ese miedo.

El problema de la violencia en la cosmovisión de Mainländer es una invitación a reflexionar cómo, a través del pensamiento, es posible desmarcar la filosofia de cualquier tipo de instrumentalización que la lleve a enaltecer el uso de la violencia como herramienta del discurso filosófico.

Recibido: 26/10/20

Aceptado: $12 / 02 / 21$

\section{Bibliografia}

Burgos Cruz, O. F., "Sobre una posible influencia de Mainländer en Freud", en: Burgos Cruz, O. F. (ed.), Philipp Mainländer. Actualidad de su pensamiento, Chilpancingo: Universidad Autónoma de Guerrero, 2019.

Freud, S., Jenseits des Lustprinzips, Leipzig/Viena/Zúrich: Internationaler Psychoanalytischer Verlag, 1920.

Freud, S., "Das ökonomische Problem des Masochismus", en: Theorie des Unbewußten, 5 (1898-1927), Leipzig/Viena: Internationaler Psychoanalytischer Verlag, 1924.

Fromm, E., The Heart of Man, its Genius for Good and Evil, Nueva York: Harper \& Row, 1964.

Fromm, E., "Prophets and Priest", en: Shoenman, R. (ed.), Bertrand Russell, Philosopher of the Century. Essays in his Honour, Boston: Little, Brown and Company/The Atlantic Monthly Press, 1968.

Fromm, E., The Anatomy of Human Destructiveness, Nueva York/Chicago/San Francisco: Holt, Rinehart and Winston, 1973.

Fromm, E., The Dogma of Christ, Londres/Nueva York: Routledge Classics, 2004.

Krafft-Ebing, R. von., Psychopathia Sexualis, Stuttgart: Verlag von Ferdinand Enke, 1886. Lütkehaus, L., Nichts, Zúrich: Haffmans, 1999.

Mainländer, P., Die Philosophie der Erlösung, v. I, Hildesheim/Zúrich/Nueva York: Georg Olms, 1996.

Mainländer, P., Die Philosophie der Erlösung, v. II, Hildesheim/Zúrich/Nueva York: Georg Olms, 1996.

Mainländer, P., Die Macht der Motive. Literarische Nachlass von 1857 bis 1875, v. IV, Hildesheim/Zúrich/Nueva York: Georg Olms, 1999.

Platón, Fedón, en: Diálogos, Martínez, J. M., E. Lledó, C. Íñigo y C. García Gual (trads.), v. III, Madrid: Gredos, 1992.

Platón, Filebo, en: Diálogos, Durán, M. A. (trad.), v. IV., Madrid: Gredos, 1992. 
Schopenhauer, A., Die Welt als Wille und Vorstellung, v. I, Stuttgart/Fráncfort del Meno: Suhrkamp Taschenbuch Verlag, 1986.

Spielrein, S., "Die Destruktion als Ursache des Werdens", en: Jahrbuch für psychoanalytische und psychopathologische Forschungen, v. IV (1912), pp. 465-503.

Sommerlad, F., "Aus dem Leben Philipp Mainländers", en: Müller-Seyfarth, M. (ed.), "Die modernen pessimisten als décadents": von Nietzsche zu Horstmann. Texte zur Rezeptionsgeschichte von Philipp Mainländers Philosophie der Erlösung, Wurzburgo: Königshausen und Neumann, 1993.

Tagore, R., Nacionalismo, Corriente Basús, F. y S. Chaparro (trads.), Madrid: Taurus, 2012 . 